\title{
Impact of Industrial Revolution 4.0 on the Labor Market in Vietnam
}

\author{
Nguyen Minh $\operatorname{Tri}^{1} \&$ Doan Thi Nhe ${ }^{2}$ \\ ${ }^{1}$ Politics and National Defense Education Center, Ho Chi Minh City University of Technology (HUTECH), Ho Chi \\ Minh City, Vietnam \\ ${ }^{2}$ Faculty of Basic Science, Van Lang University, Ho Chi Minh City, Vietnam \\ Correspondence: Nguyen Minh Tri, Politics and National Defense Education Center, Ho Chi Minh City University of \\ Technology (HUTECH), 475A Dien Bien Phu Street, Ward 25, Binh Thanh District, Ho Chi Minh City, Vietnam. \\ E-mail: nm.tri@hutech.edu.vn
}

Received: August 10, 2020

Accepted: November 18, 2020

Online Published: January 3, 2021

doi:10.5430/rwe.v12n1p94

URL: https://doi.org/10.5430/rwe.v12n1p94

\begin{abstract}
Industrial Revolution 4.0 is taking shape and has a strong impact on the global labor market. The strength of the system connecting everything and artificial intelligence as well as automation technology is changing the labor market structure of countries in the world in general and of Vietnam in particular. For the labor market, the Industrial Revolution 4.0 has created many opportunities and challenges that require managers to catch up in time to have appropriate directions and solutions to develop the labor market, and meet the requirements of the current national development career.
\end{abstract}

Keywords: industrial revolution 4.0, labor market, employment, Vietnam

\section{JEL Classification: C58, E22, G11, G13}

\section{Introduction}

In the context of the Industrial Revolution 4.0 happening strongly in the world, no one can foresee how the world will change, because of its enormous scale, scope and complexity. The country must be more proactive in response to the strong effects of the era of smart industry and modern technology. The Industrial Revolution 4.0 is developing at an exponential rate, many of which have not been envisioned, posing many problems that affect every field, especially labor and employment sectors. In the early years of the 21 st century, Vietnam has initially taken advantage of the achievements of the Industrial Revolution 4.0 to actively contribute to the development of the labor market, create jobs and ensure social security for workers, but it is also posing many challenges for labor market development in the context of deep and broad integration into the international market, so the issues need to be fully identified. The opportunities and challenges facing the strong impact of the Industrial Revolution 4.0 on the labor market in Vietnam in the process of international integration.

According to Dinh Cong Tuan in The project of EU social security system and lessons for Vietnam, has analyzed a systematic overview of the settlement of the European workforce in general and some typical countries in the process of labor policy reform in the model. "Social market" of Germany, model of "free market" of England; Swedish model of "democratic society" (Dinh, 2010).

The work of Klaus Schwab, The Fourth Industrial Revolution. In the book, the author presents contents such as: revolution the fourth industrial network, its emergence and its profound changes; and the impacts of Industrial Revolution 4.0 on all areas of social life, especially for the world labor market (Klaus, 2018).

Industrial Revolution 4.0 - Problems posed for socio-economic development and international integration of Vietnam by Tran Thi Van Hoa, presented the most fundamental issues about the birth history of the industrial revolutions; industrial trends of the Industrial Revolution 4.0; opportunities, challenges and requirements of the Industrial Revolution 4.0 for socio-economic development in general as well as for the labor market in Vietnam. From the analysis of the impact of the Industrial Revolution 4.0, the author has given directions and solutions to build and develop the capacity to innovate and think creatively to take advantage of opportunities and overcome the challenges of Industrial Revolution 4.0 in Vietnam in the coming time (Tran, 2017).

The Fourth Industrial Revolution - The Revolution of Convergence and Savings by Phan Xuan Dung. The work has 
summarized the most basic features of the fourth wave of industrial revolution taking place and attracted the special attention of the masses; the nature and impact of the fourth industrial revolution on the world labor market, security and defense. In anticipation of some of the effects of the Fourth Industrial Revolution, countries around the world have come up with breakthrough policies to take advantage of the opportunities and overcome the challenges brought by it (Phan, 2018).

The above works have explained the history of formation, nature, as well as the current situation and problems posed to the labor market in the era of the fourth industrial revolution taking place in the world and in Vietnam nowadays. Thereby, the works offer solutions to take advantage of the achievements of this revolution in the current socio-economic development process.

On the basis of inheriting the above works, the article analyzes the positive impacts and challenges of the industrial Revolution 4.0 on the development of the labor market in Vietnam, the article proposes major solutions to develop our country's labor market in the context of the Industrial Revolution 4.0.

\section{Results}

\subsection{Summary of Industrial Revolution 4.0}

Karl Marx once judged: The difference among economic eras is not what it produces but how it produces, and what labor documents. Based on this, he determined that the mortar that built rice with water was the era of feudal society, the steam engine was the period of capitalism. Steam engines reflected the results of the Industrial Revolution 1.0 (from 1784). Industrial Revolution 2.0 (from 1870) taking iron and steel as a criterion has brought civilized life, productivity increased many times compared to before. Industrial Revolution 3.0 (since 1969) with the criterion is that computers, internet and eco-engineering have brought industrial society to information society and enriched the way of receiving human information, providing a fast and cheap communication tool between enterprises or within enterprises, between production and business units and consumers... has become an important channel for people to conduct economic activities and how to enjoy.

Entering the early years of the 21 st century, the term Industrial Revolution 4.0 or the fourth industrial revolution has been mentioned a lot on media and social networks. The term "Industrial Revolution 4.0" was first mentioned at the Technology Exhibition Fair Hannover (Germany) and after officially being included in the High-Tech Strategic Action Plan adopted by Germany in 2012; officially recognized the concept and content at the 46th World Economic Forum (WEF), January 20, 2016. Klaus Schwab said: "The fourth industrial revolution formed on the foundation of the digital revolution and incorporates many technologies is driving an unprecedented rapid transformation of the model in economic, corporate, social and personal aspects. It not only changes what we are doing, our way of doing things, but also who we are in the job" (Klaus, 2018).

On May 4, 2017, Prime Minister Nguyen Xuan Phuc signed Directive 16/CT-TTg on strengthening the capacity to access the Industry 4.0, stating: "Industry 4.0 with the development trend based on the highly integrated platform of the digital - physical - biological connection system with the breakthrough of the Internet of Things and Artificial Intelligence is fundamentally changing the production of the world" (Prime Minister, 2017).

Industrial Revolution 4.0 is the combination of technology in the fields of physics, digital technology and biology, creating completely new production possibilities and having a profound impact on economics, politics, and society of the world. Four key features of the Fourth Industrial Revolution can be generalized: Firstly, based on a combination of new sensor technology, big data analytics, cloud computing and internet of things connectivity will drive the development of automation machines and smart production systems Secondly, using 3D printing technology to produce products completely by unifying production lines without the need to assemble auxiliary equipment - this technology also allows people to print new products using non-traditional methods, bypass intermediaries and reduce production costs as much as possible. Thirdly, nanotechnology and new materials create new material structures that are widely applied in almost all fields. Fourthly, artificial intelligence and cybernetics allow people to control remotely from space, time, and interact faster and more accurately. Vietnam is moving rapidly from the "golden population" structure to the aging population. Industrial Revolution 4.0 should be seen as an opportunity for us to develop the labor market, increase labor productivity based on scientific and technical applications, and effectively utilize the Golden population structure in the present. Therefore, the application of the achievements of the Industrial Revolution 4.0 has the ability to open up new opportunities for socio-economic development in general and for the development of Vietnam's labor market in particular.

\subsection{Impact of the Industrial Revolution 4.0 on the World Labor Market}

The Industrial Revolution 4.0 has a great impact on the overall socio-economic life, from the global scope to the 
regional and national levels, especially the manufacturing sector. The world economy is entering a period of growth mainly based on the motivation without a ceiling, which is technology and innovation, instead of growth mainly based on the inputs that always have a ceiling such as capital, labor and natural resources. The explosion of information systems on the internet and the ability to access vast, timely and accurate information have helped to allocate resources more effectively. Technological breakthroughs help new materials and energy sources be invented at a cheaper price than traditional materials, saving production costs.

Industrial Revolution 4.0 has a special impact on the change of labor markets of many countries, although it has just started, it has been disrupting the traditional labor market structure in many countries. At the World Economic Forum held in 2016 in Switzerland, scientists warned that, under the influence of the Industrial Revolution 4.0, the labor market will be seriously challenged because of the imbalance between labors of supply and demand. The demand for high quality labor will increase, the demand for unskilled and middle and low skilled workers will decline rapidly. The 2016 World Economic Forum predicted that Industrial Revolution 4.0 would create about 2 million new jobs in the high-tech and automation industries, but would disappear about 7 million jobs in history industries. Employing a lot of unskilled and low-skilled workers (Klaus, 2018).

In developed countries, workers are faced with the fact that artificial intelligence is gradually replacing people in many fields. A 2013 Frey \& Osborne study predicted that $47 \%$ of jobs in industry, construction and agro-forestry-fishery in the US will be replaced by robots. Instead of investing in low-cost labor countries, some investors have returned to the United States to take advantage of robotics, artificial intelligence and low transportation costs (Klaus, 2018, p.150). By the end of 2015, the Bank of England forecasts that about 95 million traditional workers will lose their jobs within the next 10-20 years in the US and the UK alone - equivalent to $50 \%$ of the workforce in the two countries (Vu, 2017). Similarly, the World Economic Forum's report predicts that 5 million jobs in 15 developed and emerging economies could be lost due to the potential impact of the Industrial Revolution 4.0 on the US, Germany, and France, China and other countries (Klaus, 2018).

Labor in the ASEAN region is also facing a strong labor structure change. In some labor-intensive industries such as textiles and clothing, robots are being introduced into production lines to work with people. According to ABD and ILO reports, two-thirds of 9.2 million textile and footwear workers in Southeast Asia are at risk, of which $88 \%$ of Cambodian and $64 \%$ of Indonesian workers are at risk. The engine was replaced by robots under the impact of the automation wave in the industry. Jobs such as the operator of the telecommunications, banking, insurance, or securities industries are also likely to disappear in the future when the automatic answering system is applied (ADB \& ILO, 2016).

The Industrial Revolution 4.0 and the formation of the ASEAN Economic Community have removed the hard border of labor markets among countries in the region, making the labor market in the bloc more vibrant, promoting job creation for each member state. However, due to uneven development, the skilled and skilled labor force mainly moves into Singapore, Malaysia and Thailand (ADB \& ILO, 2016). The rest, most of the moving workers within ASEAN are low-skilled, unskilled workers and facing the risk of unemployment as the impact of the Industrial revolution 4.0 becomes more extensive.

\subsection{Opportunities and Challenges for Vietnam's Labor Market Under the Impact of Industrial Revolution 4.0}

As well as its impacts on the world labor market, Industrial Revolution 4.0 brings both opportunities and challenges to the development of the Vietnamese labor market. The opportunities that this revolution brings may include the development of technology spaces that help to connect labor demand and supply directly and quickly compared to the traditional labor market. These technology spaces are easy to use, for example, smartphones help connect the community easily, thereby creating completely new ways of consuming goods and services. In addition, new technologies lower barriers, enabling businesses and individuals to produce wealth, material, change the working environment as well as create new career opportunities for worker. Currently, about 52\% of Vietnam's population use the internet, this is an opportunity to create more jobs in the field of information technology in the near future (Phan, 2017). In fact, the demand for labor in the information technology industry in Vietnam increases rapidly, but the human resources of the information technology industry is inadequate, unable to meet social requirements. According to VnEconomy: In 2019, the number of information technology human resources needed is 350,000, but the shortage is about 90,000. In the next two years, while the number of manpower needed is estimated at 400,000 people by 2020 and 500,000 people by 2021 , corresponding to the shortage of information technology personnel of 100,000 employees (in 2020) and 190,000 (2021).

From a market perspective, technology will change production methods, resulting in a change in human resources to implement that production method. There are jobs that are lost but there are jobs that require adaptation to meet the 
new requirements. Thus, the Industrial Revolution 4.0 will cause the labor market to have a change in labor structure, resource structure, structure of labor qualifications, with different requirements on labor skills. In particular, workers must be more resilient to respond to new jobs and avoid rejection.

Besides the opportunities, the Industrial Revolution 4.0 also poses many challenges to Vietnam's labor market in the coming time, such as:

Firstly, pressure on improving the qualifications of workers. The labor force of our country today is mainly low-skilled workers. Survey data from the General Statistics Office from 2019 to the present shows that, although the number of workers who have not yet received technical and professional training in our country, despite the downtrend, still accounts for the majority (about 70\%) of the labor force. Meanwhile, the demand for unskilled labor in Vietnam is forecast to decline sharply in the near future. Specifically, the ILO warns: in the next 10 years, about $70 \%$ of jobs in labor-intensive industries in the country, such as leather and footwear, electronics assembly, seafood processing, retail services (industry only) textiles and clothing is about $86 \%$ )... at high risk of being replaced by modern machinery and equipment (Le, 2016).

Furthermore, the quality of the labor force of the group of "skilled workers" is still not high, failing to meet the market's requirements in terms of both professional skills and foreign language skills. According to a JICA survey on the quality of Vietnamese labor in Japanese-affiliated enterprises, among 2,000 Vietnamese information technology students, only about 90 candidates, equivalent to 5\%, pass the survey in terms of expertise, of which only 40 candidates have enough English proficiency to work. According to Vietnam's 2017 E-Commerce Report, 24\% of businesses said that it was difficult to recruit personnel with information technology skills and training expertise. Compared with other countries in the region, the technical and professional qualifications of our labor force are also much lower. The trained labor force in our country is only approximately $20 \%$ while countries such as Singapore are $61.5 \%$, Malaysia is 62\%, and the Philippines is $67 \%$ (Vu, 2017).

Secondly, Industry Revolution 4.0 has transformed labor structure in economic sectors. With the Industrial revolution 4.0, traditionally labor-intensive occupations will gradually disappear and new jobs will appear. Industrial Revolution 4.0 has introduced automation systems and intelligent robots. These systems will gradually replace manual labor in the whole economy, putting great pressure on the labor market. Developing countries will face labor surplus and rising unemployment. Currently, Vietnam's labor force is relatively abundant but mainly low-skilled workers, so it is easily replaced by machines. The simple, repetitive jobs that most Vietnamese untrained workers are undertaking will gradually be replaced by machines in the future.

According to estimates by the International Labor Organization, up to $86 \%$ of the workers in the textile and footwear industries of Vietnam are at high risk of losing their jobs within the next 15 years. In addition to the gradual loss of traditional professions that use a lot of labor, the Industry 4.0 also appeared many new professions, associated with the characteristics of this revolution such as electronics, telecommunications, digitalization, computer technician, cyber security, 3D printing... In the future, workers who lose their jobs due to the development of robots and automation technology will move to these new industries. However, it is not easy to change careers, especially those that require a lot of knowledge.

Thirdly, the labor market is strongly segmented. In the Industrial Revolution 4.0, cheap labor is no longer a competitive advantage of the countries in the world. A series of old occupations will be lost and the international labor market will be strongly divided between low-skilled and high-skilled labor. Along with that, the introduction of artificial intelligence (intelligent robots) also reduces the need for low-skilled labor use. In particular, the industrial revolution 4.0 not only threatens the jobs of low-skilled workers, but even intermediate-skilled workers will be affected, if they are not equipped with these new skills - creative skills. With the rapid technological development in the future, the need for highly skilled and skilled labor is an inevitable requirement. From raising the quality requirements of human resources, the Industrial Revolution 4.0 has also changed the requirements and methods of training human resources. Training high-quality human resources to prepare for industrial revolution 4.0 has become an urgent issue that many countries around the world are concerned about.

Fourthly, the pressure on improving the innovation capacity of the workforce. According to the 2018-2019 Global Competitiveness Report, Vietnam is ranked 56/140 countries overall, but the component indicators related to innovation are very low; in which Technology absorption capacity index ranked 121; The complexity of the production process is 101; The quality of scientific research organizations is 95 . These figures show that the innovation capacity of our labor force is still limited, while this is a decisive factor in the Industrial Revolution 4.0.

The report "Evaluation of science, technology and innovation in Vietnam" of the World Bank and Organization for 
Economic Co-operation and Development (OECD) clearly shows that very few Vietnamese enterprises carry out $R \& D$ (research and development), or if any, funding for R\&D activities only accounts for a very small part of the enterprise's financial resources. R\&D statistics and related information are often fragmented, outdated and incompatible with international standards. R\&D connection between businesses and public research institutions is almost unavailable. Until now, Vietnam has hardly created any technology of national stature and export ability. The acquisition of new technology through the operation of FDI enterprises is also not effective.

Fifthly, the pressure on increasing labor productivity. One of the major constraints of our labor market is low labor productivity. According to the General Statistics Office of Vietnam, Vietnam's labor productivity in the period of 2011-2018 increased by an average of $4.8 \%$ per year, higher than the average rate of Singapore (1.4\%/year); Malaysia (2\%/year); Thailand (3.2\%/year); Indonesia (3.6\%/year); Philippines (4.4\% / year). As a result, Vietnam has narrowed the gap to ASEAN countries with higher levels of development. If in 2011, the labor productivity of Singapore, Malaysia, Thailand, and Indonesia in turn was 17.6 times higher than Vietnam's labor productivity; 6.3 times; 2.9 times and 2.4 times, by 2018 this relative distance will decrease to 13.7 times, respectively; 5.3 times; 2.7 times and 2.2 times. However, the current level of labor productivity in Vietnam is still very low compared to other countries in the region, notably, the absolute gap continues to increase. According to PPP 2011, labor productivity of Vietnam in 2018 reached 11,142 USD, only equal to 7.3\% of Singapore's productivity; $19 \%$ of Malaysia; 37\% of Thailand; $44.8 \%$ of Indonesia and 55.9\% of labor productivity of the Philippines. The difference in labor productivity (based on PPP 2011) of Singapore and Vietnam increased from 132,566 USD in 2011 to 141,276 USD in 2018; similarly, Malaysia's from 42,397 USD to 47,545 USD; Thailand from 14,985 USD to 18,973 USD (General Statistics Office of Vietnam, 2019). This low productivity is seen as an inevitable consequence of low quality of the labor force and weak capacity for innovation. Therefore, improving labor productivity is an urgent requirement for the domestic labor market to develop and meet the new requirements of the economy under the influence of the Industrial Revolution 4.0.

In the coming time, the process of globalization of production with the division and labor cooperation takes place increasingly widely between countries in the region and around the world. When we implement the new-generation free trade agreements, the barriers of economic space, goods, services, capital, science and technology, labor market are removed, the competition between countries became increasingly fierce. Currently, ASEAN has an agreement on the natural movement of human resources, and there is an agreement to recognize each other on official practice certificates for 8 free-moving occupations: auditors, architects, engineers, dentists, doctors, nurses, investigators and travelers. The recognition of mutual qualifications in occupational skills will be one of the very important conditions in the implementation of labor mobility between Vietnam and other countries in the region. But this will also be a challenge for Vietnam, because the number of skilled workers in our country is still modest, forced to accept migrant workers from other countries with higher qualifications. Next time, if the qualifications of Vietnamese workers are not improved to meet the requirements, we will lose immediately on "our country".

\subsection{Solutions for Developing Our Labor Market in the Context of Industrial Revolution 4.0}

To seize the opportunities and solve the pressures placed on the labor market in the context of industry 4.0, first of all, Vietnam needs to build high quality human resources. On that basis, appropriate policies are needed to encourage the improvement of workers' innovation and creativity as well as to create necessary policies and technical infrastructure for the developing labor market has ability to connect with the world labor market.

Firstly, the solution group builds high-quality human resources. The State needs to quickly develop and implement the national qualification framework according to international and regional practices. In the short term, it is possible to develop a regional standard framework; In the long run, international standards will be targeted. On that basis, building output standards of each level of education, especially tertiary and vocational training on the basis of the national qualification framework. When developing output standards of education levels, it is necessary to conduct research and practice surveys of the requirements of the domestic and foreign labor markets in order to closely follow the needs of the economy and in line with international standards.

Renew the content of the program, the form of enrollment and organize the training of general education, vocational training and higher education. Promote decentralization of training institutions in the direction of increasing financial autonomy, independence of training methods, and encouraging the participation of enterprises and employers in the training process. The content of the training program should combine theory and practice in parallel but need to focus on practical skills and promote creative initiative of learners. Encourage online training forms to increase opportunities for participating in professional training for employees.

In addition, the ministries, departments and branches should coordinate the evaluation and management of training 
quality according to regional and international standards. Expand and develop the system of national vocational skill evaluation and certification associated with vocational training institutions. At the same time, updating and supplementing national vocational technical standards that have been developed in the period of 2011-2015 ensure compatibility with standards of ASEAN and APEC. The State also needs to negotiate with other countries to recognize the skills and skills of workers, to ensure our country's labor force has the opportunity to access the world labor market. In addition, it is necessary to continue supporting budgets, mobilizing social resources, calling for investment to form a network of high-quality training institutions capable of training a number of industries and trades recognized by ASEAN and international countries.

The Government should have policies to encourage, create the environment and create favorable conditions to attract talented teachers, experienced scientists at home and abroad to participate in the process of human resource training and research. Researching science and technology at Vietnam's education and training establishments. Promote training and retraining of teachers at all levels according to national and international standards.

Secondly, the group of solutions to improve the innovation and creativity of the labor force. The State should accelerate the process of institutional improvement on innovation, such as the legal framework on enterprises, the Competition Law and the conditions to access finance ... These legal frameworks need to be completed and stabilized so that businesses can feel secure to invest in research and development activities. The State adopts tools such as direct capital support or tax incentives to encourage enterprises to undertake $R \& D$.

The Government should promote the implementation of policies to attract FDI enterprises to invest in the production and trading of products with a high concentration of gray matter and facilitate these activities to spread to domestic enterprises. Public - private partnership programs on R\&D and innovation should be encouraged to focus and utilize resources, and at the same time strengthen cooperation between state research institutions and domestic and FDI enterprises.

It is necessary to avoid spreading investment, pouring capital into many research facilities belonging to different channels such as the Ministry, the Ministry of Science and Technology, the Department of Science and Technology ... on the same research issue. Develop a clear strategy for division of labor among state research agencies to ensure there is no overlap, lack of resources, and the scale does not reach the optimal level in R\&D research. For universities and research facilities, it is necessary to clearly identify their strengths, needs and concerns to identify the research focus and spearhead.

Thirdly, the solution group strengthens the supply-demand connection for the labor market. The state needs to improve the legal framework for the developed labor market. It is necessary to develop and improve laws such as the Employment Law, the Minimum Wage Law, the Labor Relations Law, the Occupational Safety and Health Law, the Law on Social Insurance, the Law on Unemployment, the Law on Vocational Training ... In accordance with market rules, protecting the legitimate interests of workers and employers, and creating favorable conditions for employees to participate in the labor market, improving Qualification, meet the needs of the market. In addition, the State needs to consider and ratify conventions of the International Labor Organization related to the labor market.

The Government, primarily the Ministry of Information and Communications, should coordinate with the Ministry of Labor, Invalids and Social Affairs to develop a system to provide career-oriented information, an employment service system and an information system. The labor market makes it easy for employees and employers to grasp information and connect with each other. It is necessary to step up the application of modern technology to connect domestic and international labor supply and demand.

\section{Conclusion}

The Industrial Revolution 4.0 is having a strong impact on all areas of social life, especially the labor market in Vietnam which is deeply and widely integrating today. The article has generalized the development history of the revolutions in history, from there draw the point of view of Industrial Revolution 4.0. Industrial Revolution 4.0 is having a strong impact on all socio-economic fields. It is changing the way of production and enjoyment of people. In particular, due to the impact of the Industrial Revolution 4.0, the labor market will be seriously challenged because of the imbalance between labor supply and demand in which high-quality workers will increase, the demand for unskilled workers and middle and low-skilled workers will decline rapidly.

Vietnam is a developing country, the effects of the Industrial Revolution 4.0 are having a strong impact on all areas of social life, and especially the labor market in Vietnam is integrating deeply and widely nowadays. The Industrial Revolution 4.0 not only created favorable conditions for the development of the labor market in Vietnam, but also created challenges such as unemployment, differentiation between the rich and the poor, lagging behind countries in 
the region and the world. Therefore, it is required that Vietnam needs to synchronously implement solutions such as: high quality human resources, high capacity for innovation and creativity of the workforce, strengthening the connection between supply and demand for the market. Labor school is necessary in order to develop the Vietnamese labor market in the context of the Industrial Revolution 4.0, contributing to building a sustainable society, for human development.

\section{References}

Dinh, C. T. (2010). The project of EU social security system and lessons for Vietnam. Hanoi: National Political.

Education - Training. (2017). Industrial Revolution 4.0: Pressure to redirect human resource training. Retrieved from https://baotayninh.vn/cach-mang-cong-nghiep-4-0-ap-luc-chuyen-huong-dao-tao-nguon-nhan-luc-a88087.html

General Statistics Office of Vietnam. (2019). Press release at the Conference Improving National Labor Productivity. Retrieved from https://www.gso.gov.vn/default.aspx?tabid=382\&idmid=2\&ItemID=19315

ILO, \& ADB. (2016). ASEAN Community 2015: Managing integration towards shared prosperity and better employment. Retrieved from https://www.slideshare.net/quynhlemkt/cng-ng-asean-2015-qun-l-hi-nhp-hng-ti-thnh-vng-chung-v-vic-lm-tt-hn

Klaus, S. (2018). Fourth industrial revolution (ministry of foreign affairs and proofreading). Hanoi: National Political.

Le, T. C. (2018). The employee factor in the production force in Vietnam after 30 years of renovation. Retrieved from http://lyluanchinhtri.vn/home/index.php

Nguyen, M. T., \& Dao, T. H. (2020). Impact of industrial revolution 4.0 on education and training in Ho Chi Minh City, Vietnam. Journal of Critical Reviews. https://doi.org/10.31838/jcr.07.12.413

Nguyen, M. Tri. (2020). Impact of Economic Growth on Social Security in Vietnam. International Journal of Humanities and Social Science. https://doi.org/10.30845/ijhss.v10n3a9

Nguyen, M. T., et al.. (2020). Opportunities and challenges in promoting the role of international integration in the process of socio-economic development in Vietnam. European Journal of Social Sciences. https://doi.org/10.46827/ejpss.v3i2.796

Phan, T. T. (2017). Labor in the spiral of industrial revolution 4.0. Retrieved from https://nhandan.com.vn/chuyen-de-cuoi-tuan/lao-dong-trong-vong-xoay-cua-cuoc-cach-mang-cong-nghiep-4-0291583/

Phan, X. D. (2018). The fourth industrial revolution - the revolution of convergence and savings. Hanoi: Science and Technics.

Prime Minister. (2017). Directive on strengthening capacity to access the Fourth Industrial Revolution, number $16 /$ CT-TTg. Hanoi.

Tran, T. V. H. (2017). Industrial Revolution 4.0 - Issues for socio-economic development and international integration of Vietnam. Hanoi: National Political.

VnEconomy. (2019). Vietnam lacks 90,000 IT human resources. Retrieved from http://vneconomy.vn/viet-nam-thieu-toi-90000-nhan-luc-cong-nghe-thong-tin-nam-2019-20190816171206497.h tm\#: :text=HCM\%20v\%C3\%A0\%20H\%C3\%A0\%20N\%E1\%BB\%99i\%20ti\%E1\%BA\%BFp,nh\%C3\%A2n\%2 0s\%E1\%BB\%B1\%201\%C3\%A0\%20gi\%C3\%A1m\%20\%C4\%91\%E1\%BB\%91c

$\mathrm{Vu}, \mathrm{Q} . \mathrm{V}$. (2017). The fourth industrial revolution and the labor supply-demand problem of enterprises in Vietnam until 2020. Hanoi: National Scientific Conference.

$\mathrm{Vu}$, X. H. (2017). Industrial Revolution 4.0 - A major challenge to the labor market. Retrieved from https://nhandan.com.vn/doi-song-xa-hoi/thach-thuc-lon-voi-thi-truong-lao-dong-282103/

\section{Copyrights}

Copyright for this article is retained by the author(s), with first publication rights granted to the journal.

This is an open-access article distributed under the terms and conditions of the Creative Commons Attribution license (http://creativecommons.org/licenses/by/4.0/). 